COMENTARIO

\title{
Una nueva oportunidad para confrontar con otros ojos el pasado
}

\author{
Juan Carlos Eslava \\ Profesor asistente, Departamento de Salud Pública, Facultad de Medicina, \\ Universidad Nacional de Colombia, Bogotá, D. C., Colombia.
}

Como sabe todo aquel que, desde el interés investigador, haya explorado el terreno de la historia, siempre existe una resonancia del presente en el intento de reconstrucción del pasado. De alguna manera, siempre se aborda el estudio histórico bajo el marco que proporciona el conjunto de preocupaciones del presente y en ese sentido siempre existe, aunque sea de manera sutil, un interés contemporáneo para estudiar el pasado.

El estudio de la historia, de esta forma, cobra riqueza al proporcionar una visión de largo plazo que ayuda a comprender el fondo de los problemas $y$, por qué no decirlo, a darles profundidad y perspectiva. En el trabajo que aquí se publica sobre las repercusiones en salud de la metalurgia precolombina, este interés salta a la vista y cobra notoria repercusión para la comprensión epidemiológica.

El texto se presenta, a simple vista, como un ligero y divertido ejercicio académico pero en la medida en que se refina la mirada y se acentúa la curiosidad, el material va cobrando mayor solidez cognitiva y audacia en el esfuerzo por combinar los recursos de diferentes disciplinas científicas para esclarecer aspectos hasta ahora ignorados acerca de la realidad del enfermar en nuestros pueblos precolombinos.

No soy un experto en los temas de la paleopatología pero, por lo poco que conozco, la pregunta que se hace el autor, así como las conjeturas que arriesga, son innovadoras y ofrecen una

\footnotetext{
Correspondencia:

Juan Carlos Eslava C.

Departamento de Salud Pública, Facultad de Medicina, Universidad Nacional de Colombia, Bogotá, D. C.

Telefax: 3165000 ext 15-073

e-dirección: jceslavac@unal.edu.co

Recibido: 04/08/05; aceptado: 11/08/05
}

encantadora oportunidad para meditar acerca de las profundas relaciones que se establecen entre cultura, desarrollo tecnológico y enfermedad.

Más sugestivo aún, para quienes profesamos un especial gusto por las discusión en torno a los modelos y teorías epidemiológicas, es el matiz que adquiere el texto al proponer la crítica a un connotado referente para entender el cambio de los patrones epidemiológicos. Yo debo reconocer que no estoy seguro de compartir la opinión -y el optimismo- del autor cuando sugiere que la presencia de una enfermedad crónica como la del "pie negro" en las poblaciones precolombinas refuta la teoría de Omran de la transición epidemiológica, dado que esta teoría parte de establecer tendencias generales afirmando el predominio de un tipo de enfermedades en una época y no la negación de la posibilidad de la existencia simultánea de varios tipos de enfermedad. Sin embargo, considero que esta osada implicación, en el marco que ofrece el documento, es un acicate para el intelecto y puede servir para habilitar una interesante discusión sobre la validez del modelo de transición. La provocación es, de por sí, embriagante.

Creo que por el original encanto que produce su lectura, así como por el fascinante vínculo que se establece entre epidemiología e historia este texto merece ser leído por el público de esta reconocida revista, la cual tiene el prestigio de haberse interesado, desde siempre, por entender la complejidad de los fenómenos asociados con la enfermedad humana.

Agradezco a los editores la oportunidad que me han brindado para manifestar, de manera pública, el agrado que siento por encontrar este tipo de artículos -y las discusiones que propone- en una revista biomédica. 